\title{
Food aid supply and distribution in insecure regions: world food programme operation analysis in Ethiopia
}

\author{
Adriana Leiras $^{\mathrm{a}}$ (1), Paulo Gonçalves ${ }^{\mathrm{b}}$ (1) , Bervery Chawaguta $^{\mathrm{b}}$, Irineu de Brito Junior, ${ }^{\mathrm{c} \mathrm{d}^{*}}$ (i), \\ Hugo Tsugunobu Yoshida Yoshizakid \\ aPontifícia Universidade Católica do Rio de Janeiro, Rio de Janeiro, RJ, Brasil \\ bUniversità della Svizzera Italiana, Lugano, Switzerland \\ 'Universidade Estadual Paulista, São José dos Campos, SP, Brasil \\ dUniversidade de São Paulo, São Paulo, SP, Brasil \\ *irineu.brito@unesp.br
}

\begin{abstract}
Paper aims: This paper analyzes the food aid supply and distribution for famine relief by the World Food Programme (WFP) in Ethiopia. Food insecurity has increasingly affected people around the world. Furthermore, the characteristics of the provision of humanitarian aid in insecure regions pose several additional challenges over traditional distribution planning (e.g., corruption, losses in last-mile distribution, security escorts).

Originality: Most previous studies addressing famine relief are qualitative, with only a handful including mathematical modeling as this work. Furthermore, we validate our mathematical model with data from a real problem setting.

Research method: We propose a stochastic transshipment network flow model to ensure the efficient allocation of limited resources.

Main findings: The results show high potential for cost savings and offer managerial insights to humanitarian logisticians on the food aid supply and distribution. Our findings indicate that policies in humanitarian logistics should focus on: (a) relaxing legislation for customs clearance of humanitarian supplies; (b) strengthening local market to increase local procurement; (c) implementing tools to enhance security; and (d) monitoring distribution to mitigate the impact of corruption.

Implications for theory and practice: The results suggest that optimizing food aid distribution in Ethiopia can save millions of people vulnerable to malnutrition.
\end{abstract}

Keywords

Humanitarian logistics. Food aid supply. Food aid distribution. Stochastic optimization. Famine relief.

How to cite this article: Leiras, A., Gonçalves, P., Chawaguta, B., Brito Junior, 1., \& Yoshizaki, H. T. Y. (2021). Food aid supply and distribution in insecure regions: world food programme operation analysis in Ethiopia. Production, 31, e202 10070. https://doi.org/10.1590/0103-6513.20210070

Received: June 02, 2021; Accepted: Aug. 25, 2021.

\section{Introduction}

This paper addresses the problem of food insecurity. "More than 820 million people in the world are still hungry today, underscoring the immense challenge of achieving the Zero Hunger target by 2030. Hunger is rising in almost all subregions of Africa" (Food and Agriculture Organization, 2019). In 2015, the UN adopted the 2030 Agenda for Sustainable Development, providing a blueprint for peace and prosperity. At its heart are the 17 Sustainable Development Goals, from which Goal 2 states: "End hunger, achieve food security and improved nutrition and promote sustainable agriculture” (United Nations, 2018). 
Food insecurity has many variants that relate to circumstances such as economics and poverty, the impact of slow-onset (as drought and refugee crisis), and sudden-onset disasters (as hurricanes and earthquakes). Food insecurity nature and magnitude, for example, significantly differ in high-income countries from that in developing countries as the latter include extreme or chronic undernutrition. Providing humanitarian aid to any of those variants is a commonly used and broadly understood solution to the food insecurity problem, as food assistance in several low-income countries could make the difference between life and death (Gentilini, 2013).

This paper focuses on the challenges associated with the planning of food aid distribution in insecure regions in low-income countries. Humanitarian organizations engaged in delivering food aid to insecure areas face challenges such as uncertainty in demand, low-quality information (Mete \& Zabinsky, 2010), lack of systematic and reliable field data on route rates, route conditions, and capabilities that prevent organizations from optimizing last-mile distribution (Whybark, 2007; Balcik et al., 2008; Noyan et al., 2015), inaccessible roadwork, inadequate infrastructure, corruption, theft, hijacking, looting, political instability, and rebel activity (Chander \& Shear, 2009).

This research investigates the impact of planning decisions related to food purchasing, stock, prepositioning, and distribution in insecure areas affected by famine for the annual planning of a humanitarian organization. We propose a stochastic model for food aid supply and distribution annual planning based on a transshipment network flow model. Transshipment network flow models have been broadly applied for sudden onset disasters (Rottkemper et al., 2011; Barbarosoğlu \& Arda, 2004; Caunhye et al., 2016; Clark \& Culkin, 2013, Baskaya et al., 2017), but in this paper, we cover a type of slow-onset disaster (famine).

We address uncertainty from a two-stage mathematical programming modeling due to the two-stage nature of disaster management (Mete \& Zabinsky, 2010). The first stage decisions encompass disaster preparedness food supply and stock level. The second stage is made after the disaster occurs and is represented by the food aid distribution plan. We offer a transshipment model that minimizes food aid supply and distribution costs, considering limits for unmet demand, shortages, and human deprivation.

The model captures the physical transportation reality of providing food aid (e.g., distances traveled, available routes) and its inherent uncertainty. The uncertainty associated with "last mile" distribution impact the ability to reach beneficiaries, including issues such as lack of access to roads and hubs in flooded areas; inadequate distribution in hostile territories; high setup costs to establish new routes; and corruption payoffs in humanitarian logistics.

This work extends and updates the work by Gonçalves et al. (2013) and pays homage to the World Food Programme (WFP), the institution that won the Nobel Peace Prize in 2020 for its role in combating hunger worldwide. We collect and analyze data for WFP operations in Ethiopia's food aid distribution network, a country with constant food insecurity (Dufour et al., 2018). The WFP, the United Nations food-aid agency founded in 1961, is involved in the food movement, aid distribution, and information management in insecure regions. On average, WFP reaches more than 80 million people with food assistance in 75 countries each year (World Food Programme, 2015).

The following section presents the relevant literature. Section 3 discusses the challenges of food aid supply and distribution. Section 4 details the problem model. Section 5 provides case-specific information, describes the model application, and discusses the results. Finally, Section 6 presents our conclusions and opportunities for future research.

\section{Theoretical foundation}

Uncertainty has been addressed in mathematical programming models in various approaches (as in Dantzig, 1955; Birge \& Louveaux, 2011), among which two-stage stochastic programming is the most widespread method as it can deal with uncertainty in any one of the model parameters (Barbarosoğlu \& Arda, 2004).

Two-stage models have increasingly been applied to humanitarian operations contexts (Grass \& Fischer, 2016), Hoyos et al. (2015) - for example for emergency relief distribution (Barbarosoğlu \& Arda, 2004; Chakravarty, 2014; Alem et al., 2016; Rath et al., 2016), relief supplies prepositioning (Salmerón \& Apte, 2010; Falasca \& Zobel, 2011; Rawls \& Turnquist, 2012; Noyan et al., 2015; Charles et al., 2016; Condeixa et al., 2017), facility location (Murali et al., 2012; Brito Junior et al., 2020), and facility location considering vehicle routing (Mete \& Zabinsky, 2010; Li et al., 2012; Caunhye et al., 2015). However, the majority of the studies consider natural and sudden-onset disasters.

Most of the works regarding famine relief are conceptual (Long \& Wood, 1995; Belgasmi, 2007; Doocy et al., 2011; Maxwell et al., 2011). Few of them consider mathematical modeling. Benini (1993) presents a humanitarian assistance simulation model and uses data from Mali; Hwang (1999) offers a hypothetical application of a food 
distribution model in North Korea; whereas Paul \& Wang (2015) propose a Mixed-Integer Programming (MIP) and robust optimization model to guide USAID food supply considering logistic costs. Rancourt et al. (2015) develop location-covering models to determine a set of distribution centers where the food is directly distributed to beneficiaries in Kenya. Ferrer et al. (2018) built a compromise programming model for multi-criteria optimization in last-mile distribution using Niger 2004 famine data to illustrate the model application. Peters et al. (2021) developed a mixed-integer linear programming model to optimize the sourcing plan, the transfer modality, and the delivery of food for WFP headquarters located in Rome.

Some famine studies are focus on food banks that provide food to charities and other organizations for donating to vulnerable populations (Gentilini, 2013). Balcik et al. (2014) develop a multi-vehicle sequential allocation problem for nonprofit operations food banks in the Chicago region. Lien et al. (2014) analyze equitable and effective service in food banks. Orgut et al. (2016) create a framework for decision-making at the operational level to identify open and critical food bank aid distribution problems for more than 200 food banks in the United States. They develop deterministic capacity-constrained network flow models for maximizing effectiveness in food distribution. Davis et al. (2014) developed a covering model that enables food banks to collect donations from local sources and then deliver food to charitable agencies. They create an integrated linear programming model to minimize the total transportation cost for a scheduling and routing problem that simultaneously selects a visit combination for a food provider and charitable agency in Sydney.

Most of the famine relief literature provides theoretical models applied to synthetic data. Exceptions include simulation of the effectiveness - the degree of goal attainment - of Red Cross protection and assistance for victims of armed conflict in Mali (Benini, 1993), bidding process to procure food aid for US Department of Agriculture - USDA (Paul \& Wang, 2015), air-cargo routing in WFP Angola (Angelis et al., 2007), fleet management for IFRC (Pedraza-Martinez \& Van Wassenhove, 2013), food aid distribution form WFP and Red Cross in Kenya (Rancourt et al., 2015), and warehouse location in East Africa for United Nations Humanitarian Response Depot (UNHRD) (Dufour et al., 2018). In this context, as we use actual data from WFP Ethiopia, this paper also increases the availability of case studies in humanitarian logistics.

\section{Problem statement}

Humanitarian organizations (HOs) distribute donated humanitarian aid. Donations can be gifts-in-kind made by third parties and cash donations made by donors. Gifts-in-kind donations are challenging due to mismatches between beneficiaries' needs and the items donated. In contrast, cash donations allow HOs to purchase commodities through local or global suppliers (Lamenza et al., 2019). Local purchases have the advantage of stimulating the local economy, enjoying lower transportation costs and shorter cycle times; however, they may suffer from low quality, lower availability, and higher prices (Duran et al., 2013).

To deliver humanitarian aid in multiple demand points, HOs must decide on supply and prepositioning levels, considering uncertainty sources, warehouse capacities, and accessibility along the year, security issues, setup and distribution costs, and corruption payoffs.

HOs may operate in highly complex distribution networks, including primary and secondary transport challenges. Primary transport includes surface transport (usually by road) between an overland country and a recipient. HOs transport humanitarian aid from ports to hubs strategically located around a country. Secondary transport focuses on from one point to another in-country transportation. The distribution challenges typically include road infrastructure, port congestion, availability of overland transport, inland registered trucks, warehousing access due to road conditions, transport costs, and insecurity.

Insecure regions have a history of theft, hijacking, and looting, requiring military escort for aid distribution. The need for security escorts retards the delivery process significantly as trucks travel in convoys, changing the frequency of deliveries and increasing transportation costs. The need for military escorts in the Somali region of Ethiopia, for example, impacts transportation costs by $46 \%$ (Chander \& Shear, 2009).

Corruption in trucking operations is a relatively common additional challenge within the humanitarian sector. Corruption may also include drivers selling the food for profit, keeping rations for themselves, or; using gasoline or food as a bribe to ward off the threats, or diverting aid to rebel forces (Chander \& Shear, 2009).

Longer lead times at customs are also symptomatic problems for HOs, generating further delays.

\section{Modeling food aid supply and distribution}

We propose a two-stage stochastic linear program model to minimize the total cost of aid supply, prepositioning, and distribution. The objective function contains a deterministic term (first-stage) and the expectation of the second stage taken over all realizations of the randon event $\omega$. First-stage decisions must 
hold the costs associated with all scenarios considered, and the expected costs of the second-stage decisions are optimized (Birge \& Louveaux, 2011). Uncertainties are represented by a set of discrete scenarios $\Omega$, where $\omega(\omega \in \Omega) . P^{o}\left(P^{o} \geq 0, \sum_{\omega=1}^{|\Omega|} P^{\omega}=1\right)$ represents the probability of the occurrence of the $\omega$-th scenario. Many papers have discussed scenario representation in different contexts (see, for example, Ribas et al., 2012; Dillon et al., 2017). Further detail on methodologies for scenario generation can be found in Kouwenberg (2001).

First stage variables (i.e., here-and-now decisions) capture supply $\left(\mathrm{s}_{\mathrm{i}}\right)$ to be delivered in ports and hubs - i.e, international and local purchases, $s_{\mathrm{i}}$ and $s_{\mathrm{k}}$ respectively - and prepositioning stock decisions $\left(e_{\mathrm{k}}\right)$, while second stage variables (i.e., scenario-dependent decisions) capture distribution flows from an origin to a destination $\left(x_{i, i 1}^{\omega}\right)$ as well as the level of unmet demand in a hub or final destination point $\left(y_{i}^{\omega}\right)$. We consider demand variability (which defines $D M_{i}^{\omega}, U D_{i}^{\omega}, P T_{i}^{\omega}$ ), route availability and hub accessibility due to flooding during the rainy season (which defines $A_{i}^{\omega}, C T_{i, 11}^{\omega}, C S e_{i, i 1}^{\omega}$ ) as uncertainty sources.

Table 1 present the sets, parameters, and variables of the model. Next, the model is described.

\subsection{Model nomenclature}

Table 1

Table 1. Index sets, parameters, and variables.

\begin{tabular}{|c|c|}
\hline \multicolumn{2}{|r|}{ Indices and sets } \\
\hline 1 & Nodes; $(i, i 1) \in l$ (Ports, Hubs and FDPs are nodes $l=P \cup J \cup K$ ) \\
\hline$P$ & Ports; $p \in P \subset 1$ \\
\hline$K$ & Hubs and delivery points (extended); $k \in K \subset l$ \\
\hline$J$ & Final destination points - FDPs; $j \in J \subset l$ \\
\hline$\Omega$ & Scenarios; $\omega \in \Omega$ \\
\hline \multicolumn{2}{|r|}{ Scenario-nondependent parameters and units } \\
\hline$C F_{\mathrm{i}}$ & Purchase cost of food supplies to be delivered at node $i ; i \in P \cup K$ in USD/t. \\
\hline$F C_{\mathrm{i}}$ & Cost of corruption of food supplies to be delivered at node $i ; i \in P \cup K$ in USD/t. \\
\hline$C P_{\mathrm{k}}$ & Cost of prepositioning of food supplies (holding cost) at node $k ; k \in K$ in USD/t. \\
\hline$L P_{\mathrm{k}}$ & Upper limit for purchases of food supplies in local market to deliver at node $k \in K$ in $\mathrm{t}$ (metric-tons). \\
\hline$S C_{\mathrm{k}}$ & Capacity of storage at node $k ; k \in K$ in $\mathrm{t}$ (metric-tons). \\
\hline \multicolumn{2}{|r|}{ Scenario-dependent parameters and units } \\
\hline$D M_{i}^{\omega}$ & Node $i$ demand under scenario $\omega ; i \in K \cup J$ in t (metric-tons). \\
\hline$U D_{i}^{\omega}$ & Unmet demand upper limit for at node $i$ under scenariow; $i \in K \cup J$ in t (metric-tons). \\
\hline \multirow[t]{2}{*}{$C T_{i, i 1}^{\omega}$} & Cost of transportation from origin node $i$ to destination node $i 1$ under scenariow; $i \in P \cup K$ and $i 1 \in K U J$ in USD/t. \\
\hline & $\begin{array}{l}C T_{i, i 1}^{\omega}=C_{i, i 1}^{\omega} \times D_{i, i 1}^{\omega} \text { : The cost of transportation is given by the product of the transport rate } C_{n, n 1}^{\omega} \text { in } \mathrm{USD} /(\mathrm{km} \times \mathrm{t}) \text { and } \\
\text { the distance } D_{i, i 1}^{\omega} \text { in } \mathrm{km} \text { - from } i \text { to } i 1 \text { under scenario } \omega \text {. }\end{array}$ \\
\hline$C S e_{i, i 1}^{\omega}$ & Security cost from origin node $i$ to destination node $i 1$ under scenario $\omega ; i \in P \cup K$ and $i 1 \in K \cup J$ in USD/t. \\
\hline$A_{i}^{\omega}$ & Binary parameter indicating 1 if node $i$ is accessible by any route under scenario $\omega, 0$ otherwise; $i \in K \cup J$ and $A \in\{0,1\}$ \\
\hline$P T_{i}^{\omega}$ & Penalty for unmet demand at node $i$ at scenario $\omega, i \in K \cup J$ in USD/t. \\
\hline$P^{\omega}$ & Scenarios $\omega$ probabilities \\
\hline \multicolumn{2}{|r|}{ First-stage decision variables and units } \\
\hline$S_{\mathrm{i}}$ & The quantity of food supplies to be delivered at node $i ; i \in P \cup K$ in t (metric-tons). \\
\hline \multicolumn{2}{|r|}{ Second-stage decision variables and units } \\
\hline$x_{i, i 1}^{\omega}$ & $\begin{array}{l}\text { The quantity of food supplies transported from origin node } i \text { to destination node } i 1 \text { under scenario } \omega \text {; i } \in P \cup K \text { and } \\
i 1 \in K \cup J \text { in USD/t. }\end{array}$ \\
\hline$y_{i}^{\omega}$ & The unmet demand for food supplies at node $i$; under scenario $\omega ; \mathrm{i} \in K \cup J$ in $\mathrm{t}$ (metric-tons). \\
\hline
\end{tabular}




\subsection{Model description}

HOs receive food aid through ports $(p \in P \subset \emptyset$ ) and transport to final destination points (FDPs $-j \in J \subset I$ ) or extended delivery points (EDPs or hubs $-k \in K \subset \emptyset$ ). Local demand can also take place at EDPs. Local purchases in some EDPs can complement the HOs supply but are limited to local market conditions $\left(L P P_{\mathrm{k}}\right)$. Stocks can be prepositioned in EDPs, conditioned on available warehouse capacity $\left(S C_{k}\right)$, to address uncertainties in route availability and FDP accessibility during the rainy season. We assume that there are no cross flows between final destination points. Food aid deliveries to FDPs are routed to meet local beneficiary demand. We model the food aid supply and distribution system as a transshipment model with ports as sources, EDPs as intermediate transshipment nodes, and FDPs as destinations as follows:

$$
\operatorname{Min} \sum_{i \in P \cup K}^{|P \cup K|}\left(\left(C F_{i}+F C_{i}\right) s_{i}\right)+\sum_{k \in K}^{|K|}\left(C P_{k} e_{k}\right)+\sum_{\omega \in \mathrm{U}}^{|\Omega|} \sum_{n \in P \cup K}^{|P \cup K|} \sum_{i 1 \in K \cup J}^{|K \cup J|} P^{\omega}\left(\left(C T_{i, i 1}^{\omega}+C S e_{i, i 1}^{\omega}\right) x_{i, i 1}^{\omega}+P T_{i}^{\omega} y_{i}^{\omega}\right)
$$

The objective function minimizes the total supply and distribution cost (1) and contains a deterministic term (first-stage), which models the supply purchase and corruption payoffs $\left(\left(C F_{i}+F C_{i}\right) s_{i}\right)$, plus the stock decisions $\left(C_{k} e_{k}\right)$. The stochastic term of the Equation 1 contains the expected value of the second-stage objective $P^{\omega}\left(\left(C T_{i, i 1}^{\omega}+C S e_{i, i 1}^{\omega}\right) x_{i, i 1}^{\omega}+P T_{i}^{\omega} y_{i}^{\omega}\right)$ which models the total cost of the stochastic network flow decisions (transportation, security, and penalty costs for unmet demand) under the first-stage decisions.

The total cost minimization is subject to the prepositioned stock limit to the capacity of the EDPs $\left(e_{k} \leq L_{k} \quad \forall k \in K\right)\left(\mathrm{e}_{\mathrm{k}} \leq S C_{\mathrm{k},}, \forall k \in K\right)$ and local purchases limit at EDPs $\left(\mathrm{s}_{\mathrm{k}} \leq L P_{\mathrm{k},}, \forall k \in K\right)$.

Uncertainty arises from beneficiaries' demand for food aid and the effects of flood in some areas, leading to inaccessible routes or regions. As a consequence, unmet demand or demand not met immediately may exist. We consider demand variability (which defines $D M_{i}^{\omega}, U D_{i}^{\omega}, P T_{i}^{(\omega)}$, route availability and hub accessibility due to flooding during the rainy season (which defines $A_{i}^{\omega}, C T_{i, i l}^{\omega}, C S e_{i, i 1}^{\omega}$ ) as uncertainty sources.

We assume that the HO distributes all sourced supply; consequently, the constraints capturing the balance-of-flow rule for ports have an equal sign. Constraint (2) states that for each port $p$ and scenario $\omega$, the sum of all outflows equals the available internationally purchased supply $\left(s_{i}\right)$, considering if node $i$ is accessible by any route under scenario $\left(A_{i}^{\omega}\right)$.

$$
\sum_{i \in K \cup J}^{|K \cup J|}\left(A_{i}^{\omega} x_{k, i}^{\omega}\right) \leq s_{k}+e_{k}+\sum_{i \in P \cup K}^{|P \cup K|}\left(A_{k}^{\omega} x_{i, k}^{\omega}\right) \forall k \in k, \omega \in \Omega
$$

Constraint (3) determines that, for each hub $k$ and scenario $\omega$, the sum of all outflows $\left(\sum_{i \in K \cup J}^{|K \cup J|}\left(A_{k}^{\omega} x_{k, i}^{\omega}\right)\right.$ have to be smaller than local purchases $\left(\mathrm{s}_{\mathrm{k}}\right)$ plus the prepositioned stock $\left(\mathrm{e}_{\mathrm{k}}\right)$ and the sum of all inflows $\left.\left(\sum_{i \in P \cup K}^{|P \cup K|}\left(A_{k}^{\omega} x_{i, \mathrm{k}}^{\omega}\right)\right)\right)$.

$$
\sum_{i \in K \cup J}^{|K \cup J|}\left(A_{i}^{\omega} x_{k, i}^{\omega}\right) \leq s_{k}+e_{k}+\sum_{i \in P \cup K}^{|P \cup K|}\left(A_{k}^{\omega} x_{i, k}^{\omega}\right) \forall k \in k, \omega \in \Omega
$$

Constraints (4) and (5) calculate the unsatisfied demand for food in EDPs and FDPs, respectively. Constraint (6) limits the unmet demand at EDPs and FDPs $\left(U D_{i}^{\omega}\right)$. As it is known that the problem has "unavoidable shortages" that need to be captured to ensure viability, unmet demand costs have the role of making the problem feasible while absorbing disparities between supply and demand. The value of penalty for unmet demand is selected to ensure that such shortages are unavoidable.

$$
\begin{aligned}
& y_{k}^{\omega}=D M_{k}^{\omega}-\left(s_{k}+e_{k}+\sum_{i \in P \cup K}^{|P \cup K|}\left(A_{k}^{\omega} x_{i, k}^{\omega}\right)-\sum_{i \in K \cup J}^{|K \cup J|}\left(A_{i}^{\omega} x_{k, i}^{\omega}\right)\right) \forall k \in k, \omega \in \Omega \\
& y_{j}^{\omega}=D M_{j}^{\omega}-\sum_{n \in I \cup K}^{|I \cup K|}\left(A_{j}^{\omega} x_{i, j}^{\omega}\right) \forall j \in J, \omega \in \Omega \\
& y_{i}^{\omega}=U D_{j}^{\omega} \forall i \in K \cup J, \omega \in \Omega
\end{aligned}
$$


Finally, the non-negativity constraints: $\left(s_{i}, e_{k}, x_{i, i 1}^{\omega}, y_{i}^{\omega} \in \mathfrak{R}^{+}\right)$

\section{Problem setting at WFP Ethiopia}

While WFP operates in Ethiopia since 1968, the funding available is typically insufficient to meet all beneficiary demands (World Food Programme, 2016). WFP makes food supply, prepositioning, and distribution decisions to meet beneficiary demand in multiple points, considering uncertainty in beneficiary demand, warehouse capacities, and limited hub accessibility during the rainy season.

Ethiopia, located in the eastern part of Africa, is the second-most populous country in Africa, with 82 million people. High population growth and density coupled with uneven rainfall, severe land degradation, and low levels of investment in agriculture and livestock, drive Ethiopia's food insecurity. Notwithstanding continued efforts, such as biofortified drinks or crops for eliminating malnutrition (Yigezu \& Sanders, 2012), the government of Ethiopia needs external support to combat hunger in the country, and the WFP has collaborated in providing humanitarian aid. However, food distribution in Ethiopia poses significant logistics challenges. Ethiopia is a land-locked country bordered by Eritrea and Djibouti in the North, Somalia in the East, South Sudan and Sudan in the West, and Kenya in the South. The country is divided into nine ethnic-based regions, plus the capital, Addis Ababa, and the city administration of Dire Dawa (Figure 1). WFP operates mainly in the Somali region of Ethiopia, the most eastern of nine regional states of Ethiopia and heavily influenced by Somalia.

With no direct access to the sea, Ethiopia relies on neighboring countries' ports for international shipments. The main access port in Djibouti faces high port congestion due to competition from commercial and governmental cargo. The main rail transport to Ethiopia covers only $680 \mathrm{~km}$, connecting Djibouti to Dire Dawa. Still, inadequate maintenance and management make it a poor logistic choice for food aid distribution. In addition, Ethiopia struggles with poor road infrastructure, limited availability of overland and inland transport, and high transport rates due to insecurity and poor conditions in the Somali region of Ethiopia. Furthermore, when a drought occurs, the arid Somali region is more affected than the rest of Ethiopia. A significant amount of rain also adversely affects the Somali region, often leading to flooding, making it difficult to distribute food aid. The Somali region also has multiple crop cycles and thus a few different harvest periods. Nonetheless, they do not overlap, and the three months between June and September is considered the "hunger period" (Chander \& Shear, 2009).

Our model focuses on primary and secondary transportation. The primary transportation includes transporting humanitarian supplies from the three origin ports (Berbera, Djibouti, and Sudan) to several locations in Ethiopia. The secondary transportation encompasses transport to the Somali Region, where WFP is responsible for the

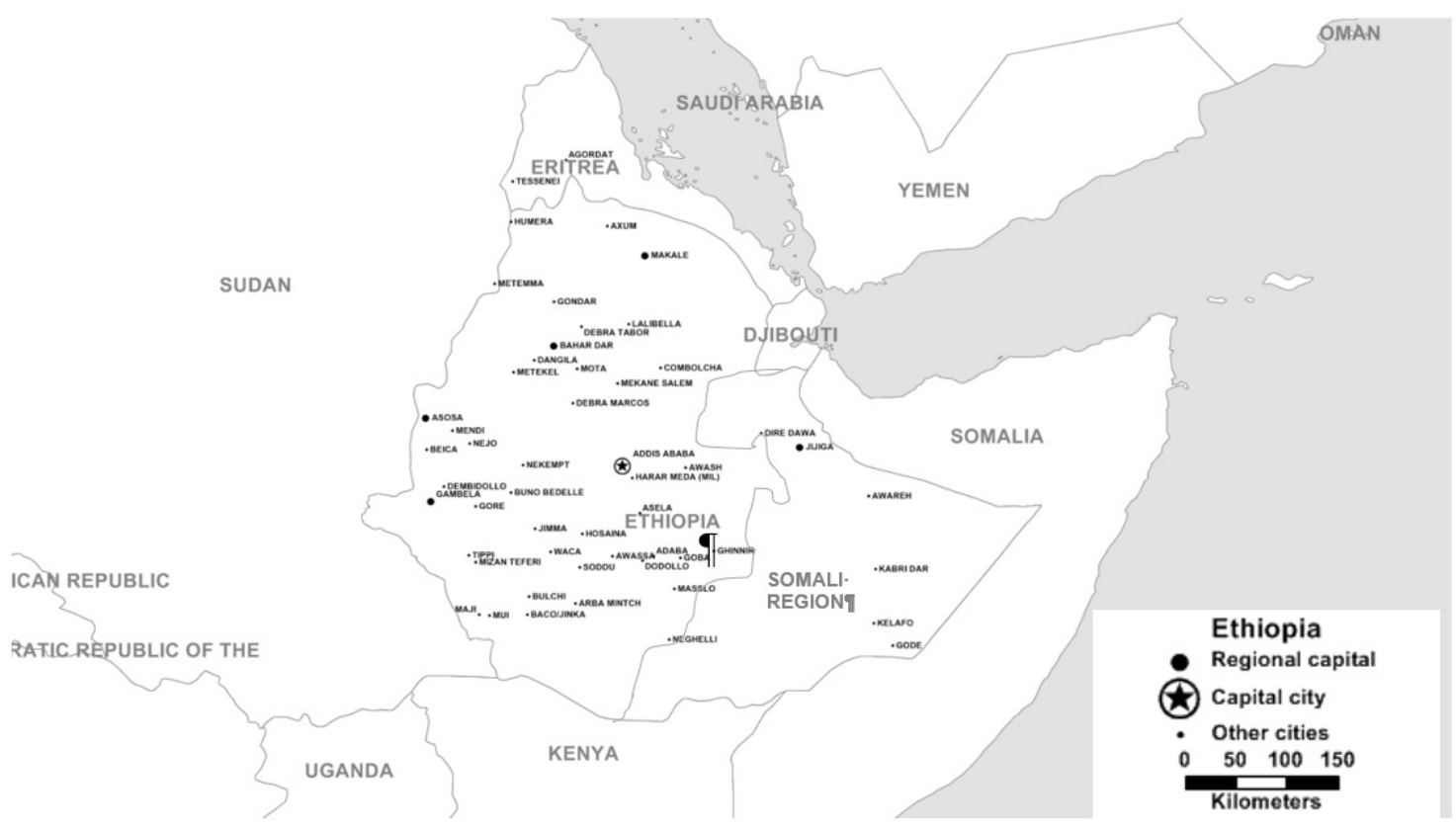

Figure 1. Horn of Africa region. Source: Adapted from Gonçalves et al. (2013). 
supply chain and in-country transportation operations. While distributing food aid, WFP faces political instability, poor infrastructure, inclement weather patterns, security concerns, and the need for military escorts, all of which endanger and delay the flow of commodities.

\subsection{Case description}

To implement our model, we use actual data from WFP Ethiopia's operations. One of the authors, a logistics officer of WFP Ethiopia, engaged in strategic discussions with colleagues in the WFP logistics department, made several field site visits to hubs and final delivery points (FDPs) in the Somali Region, and met with logistics vendors and implementing partners. Discussions with WFP Ethiopia logistics experts helped us better understand the complexity of WFP's humanitarian operations. We also reviewed the relevant WFP documents available.

The collected data encompass all food aid delivered by WFP Ethiopia for one year. WFP's logistics operations included food received in 3 ports, 13 transshipments nodes (hubs or extended delivery points - EDPs), and 54 weredas (sub-districts) that supply to more than 300 (kebeles) final destination points (FDPs). For this study, we consider the costs of food commodities $\left(C F_{n}\right)$ and prepositioning $\left(C P_{k}\right)$ are equal to $371.2 \mathrm{USD} / \mathrm{t}$ and 44.5 USD/t, respectively, and the average food demand was 970.000 t. Prepositioning costs accounted for 12\% of supply costs. Local purchases for each hub were limited up to actual supply purchases to such locations. Total local purchases were limited to up to $30 \%$ of international purchases. Unmet demand was limited up to $30 \%$ of the demand at each node. The penalty cost was set to USD 100/t. A sensitivity analysis for this value and the impact of deprivation are discussed in the next section.

The need for military escorts in the Somali region impacts transportation costs by $46 \%$ and changes the frequency of deliveries. As the aid vehicles must wait for the convoys, infrequent deliveries increase cycle inventory. Limited storage at the FDPs often results in informal town distributors, who store and distribute the unpicked-up food from their homes and take a portion of the food aid as "payment" for this position, which results in an overall 16\% loss of food - a corruption payoff (Chander \& Shear, 2009).

We define the real problem setting scenarios based on the collected primary and secondary data. The scenarios (15) represent seasonality effects throughout the year (such as the rainy season or "hunger period") that affect hub accessibility and beneficiaries' demand. Both scenarios and associated probabilities were discussed and validated by WFP Ethiopia's logistics experts in an expert panel, as suggested by Salmerón \& Apte (2010) and Brito Junior et al. (2020). Table 2 presents the possible realizations and the associated probabilities of the stochastic parameters assuming that the random variables (demand and hub accessibility) are independent.

High and low demand scenarios consider $20 \%$ of deviation from the average demand. Given the regional topology, seasonal rains and flooding may also affect the accessibility of hubs in two different regions. In region 1, flooding may limit access to two locations (Addis Ababa and Legetafo); in region 2, it may restrict access to Gode and Kebri Dehar. We consider both cases where (a) roads reaching regions 1 and 2 from the North are not accessible during the rainy season, requiring access by alternative routes, and (b) all roads reaching these regions are not accessible, requiring the hub to shut down. In a hub shut-down, the demand traditionally met by shipments from that hub could be met by a nearby hub (e.g., Dire Dawa can substitute for hubs in region 1 and Degehabur for those in region 2).

\subsection{Results and discussions}

The model was implemented using the AIMMS 3.13, CPLEX solver 12.5.1 and solved in 0.06 seconds in an Intel Core $i 7^{\circledR} 2.6 \mathrm{GHz}, 8 \mathrm{~Gb}$ RAM, 64-bit Windows $10^{\circledR}$ machine, considering 13,630 variables; 2,258 constraints; and 65,927 nonzeros. The reduced time is because the reduced number of nodes and shortages do not occur in all scenarios.

The optimal solution in Table 3 shows that WFP Ethiopia can significantly reduce current supply procurement, stock, and distribution costs.

WFP Ethiopia handled over 970,000 metric tons ( $t$ ) of food aid in one year, with an associated supply cost of USD 360 million, a stock cost of USD 43 million, and a distribution cost of over USD 65 million for transportation from ports to final delivery points. Taking the demand at hubs and final destination points as inputs to our model, the deterministic solution shows stock costs of USD 77 million and distribution costs of USD 43 million, without affecting service level. Hence, the optimal supply and distribution of commodities would lead to potential cost savings of USD 68 million (14.1\% of the total USD4 90 million program cost). These savings would allow WFP to feed an additional 127,751 people for an entire year (considering food basket 
Table 2. Possible realizations and probabilities of the stochastic parameters.

\begin{tabular}{|c|c|c|c|c|c|}
\hline \multirow{2}{*}{ Parameter } & \multirow{2}{*}{ Seasonality effects } & & \multicolumn{3}{|c|}{$\begin{array}{c}\text { Demand } \\
\text { (define } D M_{i}^{\omega}, U D_{i}^{\omega} \text { and } P T_{i}^{\omega} \text { ) }\end{array}$} \\
\hline & & & Base & High & Low \\
\hline \multirow{5}{*}{$\begin{array}{l}\text { Hub accessibility (define } A_{n}^{\omega} \text {, } \\
T C_{n, n 1}^{\omega} \text {, and } S e C_{n, n 1}^{\omega} \text { ) }\end{array}$} & Normal conditions (no flooding) & $(40 \%)$ & $P^{\omega 1}(20 \%)$ & $P^{\omega 6}(12 \%)$ & $P^{\omega 11}(8 \%)$ \\
\hline & Region 1 without access by North & $(20 \%)$ & $P^{\omega 2}(10 \%)$ & $P^{\omega 7}(6 \%)$ & $P^{\omega 12}(4 \%)$ \\
\hline & Hubs shut down in Region 1 & $(10 \%)$ & $P^{\omega 3}(5 \%)$ & $P^{\omega 8}(3 \%)$ & $P^{\omega 13}(2 \%)$ \\
\hline & Region 2 without access by North & $(20 \%)$ & $P^{\omega 4}(10 \%)$ & $P^{\omega 9}(6 \%)$ & $P^{\omega 14}(4 \%)$ \\
\hline & Hubs shut down in Region 2 & $(10 \%)$ & $P^{\omega 5}(5 \%)$ & $P^{\omega 10}(3 \%)$ & $P^{\omega 15}(2 \%)$ \\
\hline
\end{tabular}

Table 3. Model Results x Actual Data (USD x 106).

\begin{tabular}{cccc}
\hline Costs & Deterministic Solution & Stochastic Solution & Actual data \\
\hline Supply & 291.44 & 329.25 & 360.15 \\
Corruption & 4.54 & 7.33 & 18.00 \\
Stock & 76.95 & 76.95 & 43.22 \\
Transportation & 43.33 & 39.35 & 65.16 \\
Security & 1.56 & 0.68 & - \\
Penalty & - & 30.00 & 486.53 \\
Total & 417.83 & 483.57 & 2.97 \\
Savings & 68.71 & & \\
\hline
\end{tabular}

costs equal to USD 44.82/person/month) or provide meals for 1,374,000 children (considering the cost of USD 50 to feed a child for an entire school year).

Table 3 also presents the stochastic solution considering the 15 scenarios of our case study. Compared to the deterministic solution, the stochastic solution increases total costs by 16\% (USD 66 million). While transportation costs decrease in both instances and stock costs are the same, a total increase comes from supply and penalty costs arising from addressing the uncertainty in demand and hub accessibility in the model.

In addition, corruption and security costs affect distribution in Somali Region. To consider these costs as separate terms in the objective function may highlight the need to invest in policies to decrease the effects of corruption and local insecurity in the results of the WFP. Monitoring food aid distribution may be an effective way to mitigate the impact of corruption, whereas implementing tools such as Radio Frequency ldentification (RFID) or Global Positioning Systems (GPS) may enhance the security of humanitarian operations (Chander \& Shear, 2009).

The presented savings are reached by optimizing purchasing and prepositioning stock decisions to use of food aid available in local markets and hubs storage capacities, as shown in Table 4.

In the deterministic model solution, local supply (supplied to nodes that are not the ports Berbera, Djibouti, and Sudan) and prepositioned stocks represent 34\% (331,889 t) of the total supply and stock costs. As a result of using locally available food aid and carry-overs, the total amount transported decreases, leading to savings in transportation costs. Furthermore, the optimal solutions also suggest that WFP can shut down some hubs (e.g., Shinile and Sudan) while maintaining the effectiveness of its operations. Table 4 also presents the stochastic model first-stage decisions, highlighting that the total stochastic solution is $10 \%$ higher than the deterministic ones. These additional amounts are needed to minimize unmet demand in the scenarios with high demand and act as a food prepositioning policy to deal with the impact of the rainy season. However, the total amount locally purchased and stocked follows a similar profile of the deterministic solutions of the entire supply and stock costs. The supply in Djibouti and Dire Dawa contribute to the main differences between the stochastic and deterministic solutions. These differences total 108,908 $t$ and represent 13.9\% of the value of the deterministic solution.

Reducing lead times at customs may also contribute to decreasing prepositioned stocks. Turner (2013) proposes policy recommendations for reductions in customs lead times. Local policy actions such as human resource task allocation and better planning for overtime working schedules can increase the local customs capacity. Automating customs approval processes can make great strides in reducing the approval time. Other policy actions that can reduce customs' lead times include reducing bureaucracy, improving paperwork quality, 
proper documentation, preparing a local consignee, and better information sharing between different customs offices. International organizations can also ensure they are correctly registered as tax-exempt organizations in the country to which they wish to ship relief consignments. Relaxing legislation for customs clearance of humanitarian supplies is also a practice followed by several countries in the aftermath of disasters (World Customs Organization, 2015).

WFP can experience significant savings in primary and secondary transport costs with optimal supply and prepositioned decisions, as shown in Table 5. Considering the deterministic solution, most savings (66\% of the total or USD 14 million) come from optimized primary transportation. Savings in secondary transportation account for 34\% or USD 7.4 million.

In the stochastic model, the flow variables are scenario-dependent. As a result, primary and secondary costs vary according to each scenario. However, the weighted average of primary costs equals USD 29.82 million (75.8\%), and secondary costs equal USD 9.54 million (24.2\%).

Supply availability is affected by weather conditions, which may cause drought or flooding. Table 6 presents a sensitivity analysis of the original local supply limit (30\% of international purchases). The sum of total supply and stock are the same for the three cases $(1,072,235 \mathrm{t})$, but the supply and stock levels vary for each case, causing a slight variation in total cost. If the local purchases limit increases, the stock level decreases (decreasing prepositioning expenses). Thus, the results may encourage the organization to invest in policies to strengthen the local market. It is well understood that stable local economies are better in logistics because local procurement results in faster distribution. Moreover, local procurement is a strategy that goes in line with long-term development in affected regions.

Table 7 shows the unmet demand according to scenarios, and the fractions of demand served, representing the met demand. The fraction of demand served is the weighted average from the scenario probabilities and the demand served. Unmet demand occurs only in high demand scenarios, that exceeds Supply + Stock from Stochastic Solution (Table 4: 1,072,235).

Table 4. Deterministic and Stochastic model decisions for supply and stock allocation.

\begin{tabular}{|c|c|c|c|c|}
\hline \multirow{2}{*}{ Node } & \multicolumn{2}{|c|}{ Deterministic Solution } & \multicolumn{2}{|c|}{ Stochastic Solution (First Stage Decisions) } \\
\hline & Supply (t) & Stock (t) & Supply (t) & Stock $(\mathrm{t})$ \\
\hline Addis Ababa & 22,364 & & 22,364 & \\
\hline Awassa & 5,970 & 500 & 5,970 & 500 \\
\hline Berbera & 109,171 & & 105,876 & \\
\hline Degehabur & 25,505 & 5,700 & 25,505 & 5,700 \\
\hline Dire Dawa & & 56,500 & 42,647 & 56,500 \\
\hline Djibouti & 528,790 & & 591,539 & \\
\hline Dukem & 5,440 & & 5,440 & 500 \\
\hline Gode & 25,489 & 5,200 & 25,489 & 5,200 \\
\hline \multicolumn{5}{|l|}{ Hartichek } \\
\hline Jijiga & & 16,500 & & 16,500 \\
\hline Kebri Dehar & 10,030 & 5,725 & 10,030 & 5,725 \\
\hline Kombolcha & 1,376 & 19,450 & 1,376 & 19,450 \\
\hline legetafo & 5,011 & 500 & 5,011 & 500 \\
\hline Mekele & 2,925 & 20,500 & 2,925 & 20,500 \\
\hline Nazareth & 42,942 & 54,045 & 42,942 & 54,045 \\
\hline Shinile & 217 & 500 & & \\
\hline \multicolumn{5}{|l|}{ Sudan } \\
\hline Total & 785,230 & 185,120 & 887,115 & 185,120 \\
\hline Supply + Stock & \multicolumn{2}{|c|}{970,350} & \multicolumn{2}{|c|}{$1,072,235$} \\
\hline
\end{tabular}

Table 5. Delivery Costs Results x Actual Data (USD x 106).

\begin{tabular}{cccc}
\hline Costs & Deterministic Solution & Stochastic Solution & Actual data \\
\hline Primary & 33.92 & 29.82 & 48.35 \\
Secondary & 9.41 & 9.54 & 16.81 \\
Total & 43.33 & 39.35 & 65.16 \\
Savings & 21.83 & 25.81 & \\
\hline
\end{tabular}


As penalties arise from uncertainty, the penalty costs are only present in the stochastic solution. King \& Wallace (2012) recommend a parametric analysis of penalty values. With the penalty cost set to USD 100/t, the total unmet demand is concentrated in the final destination points for the scenarios with high demand. It equals $92.18 \mathrm{t}$ for each scenario 6, 7, and 9 (Table 7). For scenarios 8 and 10, we consider a high demand and that hubs in regions 1 and 2 shut down, respectively. As a result, there is no unmet demand in scenario 8; for scenario 10, the unmet demand reaches $31.76 \mathrm{t}$.

Studies about deprivation estimates functions for water (Pérez-Rodríguez \& Holguín-Veras, 2016; HolguínVeras et al., 2016). An analysis to establish an exact penalty value could not be made, but an order of magnitude assessment for a possible deprivation was possible using these water-related functions. Two situations were analyzed: (1) considering the water deprivation function proposed by Pérez-Rodríguez \& Holguín-Veras (2016); and (2) changing the functions proposed by Holguin-Veras et al. (2016) and the number of days of water deprivation ( 5 days) considered by Holguín-Veras et al. (2013). In both cases, food consumption of $550 \mathrm{~g}$ per person/day (World Food Programme, 2011) and 14 days the survival time without food (LaMont-Gregory et al., 1995) were also considered. Considering the two situations, the minor order of magnitude obtained was according to the adjusted Holguin-Veras et al. (2016) functions, and it was $5 \times 10^{3} \mathrm{USD} / \mathrm{t}$, showing that, if the deprivation costs are considered, the situation with a penalty above $136 \mathrm{USD} / \mathrm{t}$ (Table 8) is applicable, and the

Table 6. Sensitivity analysis of local purchases.

\begin{tabular}{ccccc}
\hline Instance & Total Cost $\left(\right.$ USD $\left.\times 10^{6}\right)$ & Total Supply $(\mathrm{t})$ & Total Stock $(\mathrm{t})$ & Unmet demand FDPs $(\mathrm{t})$ \\
\hline Original local supply limit & 483.57 & 887,115 & 185,120 & 308,317 \\
$50 \%$ reduction & 486.93 & 882,115 & 190,120 & 306,438 \\
$100 \%$ increase & 481.06 & 962,160 & 110,075 & 308,317 \\
\hline
\end{tabular}

Unmet demand at Hubs are zero.

Table 7. Unmet demand according to scenarios and fractions of demand served.

\begin{tabular}{|c|c|c|c|c|}
\hline Scenario & Probability & Demand $(t)$ & Unmet demand $(\mathrm{t})$ & Demand served \\
\hline 1 & $20 \%$ & 970.35 & & $100.00 \%$ \\
\hline 2 & $10 \%$ & 970.35 & & $100.00 \%$ \\
\hline 3 & $5 \%$ & 776.42 & & $100.00 \%$ \\
\hline 4 & $10 \%$ & 970.35 & & $100.00 \%$ \\
\hline 5 & $5 \%$ & 920.00 & & $100.00 \%$ \\
\hline 6 & $12 \%$ & $1,164.42$ & 92.18 & $92.08 \%$ \\
\hline 7 & $6 \%$ & $1,164.42$ & 92.18 & $92.08 \%$ \\
\hline 8 & $3 \%$ & 931.70 & & $100.00 \%$ \\
\hline 9 & $6 \%$ & $1,164.42$ & 92.18 & $92.08 \%$ \\
\hline 10 & $3 \%$ & $1,104.00$ & 31.76 & $97.12 \%$ \\
\hline 11 & $8 \%$ & 776.28 & & $100.00 \%$ \\
\hline 12 & $4 \%$ & 776.28 & & $100.00 \%$ \\
\hline 13 & $2 \%$ & 621.13 & & $100.00 \%$ \\
\hline 14 & $4 \%$ & 776.28 & & $100.00 \%$ \\
\hline 15 & $2 \%$ & 736.00 & & $100.00 \%$ \\
\hline Fraction of demand served & & & $98.01 \%$ & \\
\hline
\end{tabular}

Table 8. Solution sensitivity to changes in the penalty for unmet commodities demand (t).

\begin{tabular}{cccccr}
\hline \multirow{2}{*}{ Penalty (USD/t) } & \multicolumn{3}{c}{ Hubs } & & \multicolumn{2}{c}{ FDPs } \\
\cline { 2 - 3 } \cline { 5 - 6 } & Unmet demand & Scenarios & & Unmet demand & Scenarios \\
\hline 5 & $1,255,950$ & $1,2,4,5,6,7,9,10$ & & $1,027,352$ & $1-15$ \\
10 & $1,255,950$ & $1,2,4,5,6,7,9,10$ & & 828,609 & $1-15$ \\
20 & 857,613 & $6,7,9,10$ & 606,111 & $1-2,4-10$ \\
25 & 543,836 & $6,7,9,10$ & 368,740 & $6,7,9,10$ \\
30 & 231,316 & $6,7,9$ & 319,850 & $6,7,9,10$ \\
31 & & & 308,317 & $6,7,9,10$ \\
100 & & & 308,317 & $6,7,9,10$ \\
136 & & & & \\
\hline
\end{tabular}


model results present no unmet demand. Table 8 shows a sensitivity analysis exploring the impact of penalty costs on unmet beneficiary demand. We assume a penalty cost of USD 100/t, the highest cost in which the scenarios still present some unmet demand in FDPs. Hence, we report conservative results of our model since we maintain the service level to beneficiaries while addressing the available uncertainty. The penalty costs of USD 136/t, allows us to avoid any unmet demand.

\section{Conclusions and future research}

We analyzed the food aid supply and distribution planning of the WFP operations in Ethiopia through a two-stage stochastic linear programming model, considering uncertainties in demand and road/ hubs accessibility in flooded areas during the rainy season. Our results suggest that WFP Ethiopia can significantly improve its food aid supply and distribution system, saving millions of dollars every year. As deterministic solutions may become infeasible when nominal data changes, higher costs in the stochastic solutions reflect optimal decisions under uncertainty scenarios. The analysis was presented to and the insights discussed with the WFP logistics team. The results may help WFP plan future food aid movement; to identify optimal routes and load point locations (ports, hubs, and final delivery points); and prepare budget forecasts for food aid transportation.

This work also highlighted the importance of the systematic collection of distribution rate data and mapping road and security conditions. The data requirements necessary to implement even simple optimization models are huge and frequently met with skepticism. Ad hoc data collection is complex and would yield limited results; hence, more systematic approaches are required. By making additional information available and accessible to their logisticians (e.g., food aid pipeline reports, project activity, delivered tonnage, delivery time frames, transportation schedules, transportation rates, and warehouse location), humanitarian organizations could improve opportunities for the planning of food aid deliveries.

Besides the focus on the WFP case study, we believe that the model may be a helpful decision support tool to other humanitarian organizations in similar situations. The model may also bring managerial insights for humanitarian logisticians to discuss humanitarian relief policies, such as corruption payoffs, security, setup costs of new routes; limited local market; and funding levels. Through a cost-based analysis, the organization may decide to invest in implementing tools to enhance security, monitoring food aid distribution to avoid corruption, improving regularity in funding levels, and strengthening the local market to increase local procurement.

Short-term horizons and project-specific funding often characterize humanitarian operations. Both factors create a preference for short-term emphasis. Such a myopic focus prevents organizations from harvesting many opportunities for improvement. Instead, the focus remains on ad hoc food allocations, last-minute requests, and changes, poor coordination of port arrivals, port congestions, lack of truck capacity, inaccessibility of regions due to seasonal rains, poor road infrastructure, exposure to high transportation rates, collusion by transporters, etc. While these problems challenge the distribution of food aid, further investment in understanding their causes and collecting data will provide opportunities to address them in future models adequately. As humanitarian logistics typically exhibit limited relief aid capacity, it becomes critical to optimize the allocation of available resources effectively and equitably. Future studies could also include equity concerns, when there is a shortage of relief aid. Lien et al. (2014), for example, use an objective function that maximizes the expected minimum fill rate among customers to maintain a specified level of equity. Multi-criteria methods can also be used when considering qualitative criteria in the decision-making process (Brito Junior et al., 2020).

\section{Plain language summary}

This research analyzes the food aid supply and distribution by the World Food Programme (WFP) in Ethiopia using a two-stage stochastic transshipment network flow model that considers the challenges of providing humanitarian aid in insecure regions (e.g., corruption, losses due to last-mile distribution, security escorts).

\section{References}

Alem, D., Clark, A., \& Moreno, A. (2016). Stochastic network models for logistics planning in disaster relief. European Journal of Operational Research, 255(1), 187-206. http://dx.doi.org/10.1016/j.ejor.2016.04.041.

Angelis, V., Mecoli, M., Nikoi, C., \& Storchi, G. (2007). Multiperiod integrated routing and scheduling of World Food Programme cargo planes in Angola. Computers \& Operations Research, 34(6), 1601-1615. http://dx.doi.org/10.1016/j.cor.2005.07.012.

Balcik, B., Beamon, B. M., \& Smilowitz, K. (2008). Last mile distribution in humanitarian relief. Journal of Intelligent Transport Systems, 12(2), 51-63. http://dx.doi.org/10.1080/15472450802023329. 
Balcik, B., Iravani, S., \& Smilowitz, K. (2014). Multi-vehicle sequential resource allocation for a nonprofit distribution system. IIE Transactions, 46(12), 1279-1297. http://dx.doi.org/10.1080/0740817X.2013.876240.

Barbarosoğlu, G., \& Arda, Y. (2004). A two-stage stochastic programming framework for transportation planning in disaster response. The Journal of the Operational Research Society, 55(1), 43-53. http://dx.doi.org/10.1057/palgrave.jors.2601652.

Baskaya, S., Ertem, M. A., \& Duran, S. (2017). Pre-positioning of relief items in humanitarian logistics considering lateral transhipment opportunities. Socio-Economic Planning Sciences, 57, 50-60. http://dx.doi.org/10.1016/j.seps.2016.09.001.

Belgasmi, D. (2007). Emergency operations: Darfur, a case study. Refugee Survey Quarterly, 26(4), 243-249. http://dx.doi.org/10.1093/ rsq/hdi0286.

Benini, A. A. (1993). Simulation of the effectiveness of protection and assistance for victims of armed conflit (Sepavac): an example from Mali, West Africa. Journal of Contingencies and Crisis Management, 1(4), 215-228. http://dx.doi.org/10.1111/j.1468-5973.1993. tb00113.x

Birge, J. R., \& Louveaux, F. (2011). Introduction to Stochastic Programming. New York: Springer Science \& Business Media. http:// dx.doi.org/10.1007/978-1-4614-0237-4.

Brito Junior, 1., Leiras, A., \& Yoshizaki, H. T. Y. (2020). A multi-criteria stochastic programming approach for pre-positioning disaster relief supplies in Brazil. Production, 30, e20200042. http://dx.doi.org/10.1590/0103-6513.20200042.

Caunhye, A. M., Li, M., \& Nie, X. (2015). A location-allocation model for casualty response planning during catastrophic radiological incidents. Socio-Economic Planning Sciences, 50, 32-44. http://dx.doi.org/10.1016/j.seps.2015.02.001.

Caunhye, A. M., Zhang, Y., Li, M., \& Nie, X. (2016). A location-routing model for prepositioning and distributing emergency supplies. Transportation Research Part E, Logistics and Transportation Review, 90, 161-176. http://dx.doi.org/10.1016/j.tre.2015.10.011.

Chakravarty, A. K. (2014). Humanitarian relief chain: rapid response under uncertainty. International Journal of Production Economics, 151, 146-157. http://dx.doi.org/10.1016/j.jpe.2013.10.007.

Chander, V., \& Shear, L. (2009). An analysis of World Food Programme operations in the Somali region of Ethiopia (Maters thesis) Massachusetts Institute of Technology, Boston.

Charles, A., Lauras, M., Van Wassenhove, L. N., \& Dupont, L. (2016). Designing an efficient humanitarian supply network. Journal of Operations Management, 47-48(1), 58-70. http://dx.doi.org/10.1016/j.jom.2016.05.012.

Clark, A., \& Culkin, B. (2013). A network transshipment model for planning humanitarian relief operations after a natural disaster. In B. Vitoriano, J. Montero \& D. Ruan (Eds.), Decision aid models for disaster management and emergencies (pp. 233-257). Paris: Atlantis Press. http://dx.doi.org/10.2991/978-94-91216-74-9_11.

Condeixa, L. D., Leiras, A., Oliveira, F., \& Brito Junior, 1. (2017). Disaster relief supply pre-positioning optimization: a risk analysis via shortage mitigation. International Journal of Disaster Risk Reduction, 25, 238-247. http://dx.doi.org/10.1016/j.ijdrr.2017.09.007.

Dantzig, G. (1955). Linear programming under uncertainty. Management Science, 50(12), 1764-1769.

Davis, L. B., Sengul, 1., lvy, J. S., Brock, L. G., \& Miles, L. (2014). Scheduling food bank collections and deliveries to ensure food safety and improve access. Socio-Economic Planning Sciences, 48(3), 175-188.

Dillon, M., Oliveira, F., \& Abbasi, B. (2017). A two-stage stochastic programming model for inventory management in the blood supply chain. International Journal of Production Economics, 187, 27-41. http://dx.doi.org/10.1016/j.jpe.2017.02.006.

Doocy, S., Sirois, A., Anderson, J., Tileva, M., Biermann, E., Storey, J. D., \& Burnham, G. (2011). Food security and humanitarian assistance among displaced Iraqi populations in Jordan and Syria. Social Science \& Medicine, 72(2), 273-282. http://dx.doi.org/10.1016/j. socscimed.2010.10.023. PMid:21168249.

Dufour, É., Laporte, G., Paquette, J., \& Rancourt, M.-Ė. (2018). Logistics service network design for humanitarian response in East Africa. Omega, 74, 1-14. http://dx.doi.org/10.1016/j.omega.2017.01.002.

Duran, S., Ergun, O., Keskinocak, P., \& Swann, J. (2013) Humanitarian logistics: advanced purchasing and pre-positioning of relief items. In J. BOOKBINDER (Ed.), Handbook of Global Logistics, International Series in Operations Research and Management Science (pp. 447-462). New York: Springer. http://dx.doi.org/10.1007/978-1-4419-6132-7_18.

Falasca, M., \& Zobel, C. W. (2011). A two-stage procurement model for humanitarian relief supply chains. Journal of Humanitarian Logistics and Supply Chain Management., 1(2), 151-169. http://dx.doi.org/10.1108/20426741111188329.

Ferrer, J. M., Martín-Campo, F. J., Ortuño, M. T., Pedraza-Martínez, A. J., Tirado, G., \& Vitoriano, B. (2018). Multi-criteria optimization for last mile distribution of disaster relief aid: test cases and applications. European Journal of Operational Research, 269(2), 501515. http://dx.doi.org/10.1016/j.ejor.2018.02.043.

Food and Agriculture Organization, International Fund for Agricultural Development, United Nations International Children's Emergency Fund, World Food Programme, World Health Organization. (2019). The State of Food Security and Nutrition in the World 2019. Safeguarding against economic slowdowns and downturns. Rome: FA0.

Gentilini, U. (2013). Banking on Food: the state of food banks in high-income countries. IDS Working Papers, 2013(415), 1-18.

Gonçalves, P., Leiras, A., Chawaguta, B., \& Yoshizaki, H. T. Y. (2013). Stochastic optimization of humanitarian aid supply and distribution for the WFP in Ethiopia. In K. Singhal (Ed.), 24th Annual POMS Conference - Production and Operations Management Society. Denver, Colorado: Integrating Practice in POM Research and Teaching.

Grass, E., \& Fischer, K. (2016). Two-stage stochastic programming in disaster management: a literature survey. Surveys in Operations Research and Management Science, 21(2), 85-100. http://dx.doi.org/10.1016/j.sorms.2016.11.002.

Holguín-Veras, J., Amaya-Leal, J., Cantillo, V., Van Wassenhove, L. N., Aros-Vera, F., \& Jaller, M. (2016). Econometric estimation of deprivation cost functions: a contingent valuation experiment. Journal of Operations Management, 45(1), 44-56. http://dx.doi. org/10.1016/j.jom.2016.05.008.

Holguín-Veras, J., Pérez, N., Jaller, M., Van Wassenhove, L. N., \& Aros-Vera, F. (2013). On the appropriate objective function for post-disaster humanitarian logistics models. Journal of Operations Management, 31(5), 262-280. http://dx.doi.org/10.1016/j.jom.2013.06.002.

Hoyos, M. C., Morales, R. S., \& Akhavan-Tabatabaei, R. (2015). OR models with stochastic components in disaster operations management: a literature survey. Computers \& Industrial Engineering, 82, 183-197. http://dx.doi.org/10.1016/j.cie.2014.11.025. 
Hwang, H.-S. (1999). A food distribution model for famine relief. Computers \& Industrial Engineering, 371-2), 335-338. http://dx.doi. org/10.1016/S0360-8352(99)00087-X.

King, A. J., \& Wallace, S. W. (2012). Modeling with Stochastic Programming (pp. 33-60). New York: Springer New York. http://dx.doi. org/10.1007/978-0-387-87817-1_2.

Kouwenberg, R. (2001). Scenario generation and stochastic programming models for asset liability management. European Journal of Operational Research, 134(2), 279-292. http://dx.doi.org/10.1016/S0377-2217(00)00261-7.

Lamenza, A. A. S., Fontainha, T. C., \& Leiras, A. (2019). Purchasing strategies for relief items in humanitarian operations. Journal of Humanitarian Logistics and Supply Chain Management, 9(2), 151-171. http://dx.doi.org/10.1108/JHLSCM-09-2018-0060.

LaMont-Gregory, E., Henry, C. J. K., \& Ryan, T. J. (1995). Evidence-based humanitarian relief interventions. Lancet, 346(8970), $312-313$. http://dx.doi.org/10.1016/S0140-6736(95)92199-0. PMid:7630268.

Li, A. C. Y., Nozick, L., Xu, N., \& Davidson, R. (2012). Shelter location and transportation planning under hurricane conditions. Transportation Research Part E, Logistics and Transportation Review, 48(4), 715-729. http://dx.doi.org/10.1016/j.tre.2011.12.004.

Lien, R. W., Iravani, S. M. R., \& Smilowitz, K. R. (2014). Sequential resource allocation for nonprofit operations. Operations Research, 62, 301-317.

Long, D. C., \& Wood, D. F. (1995). The logistics of famine relief. Journal of Business Logistics, 16(1), 213-230.

Maxwell, D., Young, H., Jaspars, S., Frize, J., \& Burns, J. (2011). Targeting and distribution in complex emergencies: participatory management of humanitarian food assistance. Food Policy, 36(4), 535-543. http://dx.doi.org/10.1016/j.foodpol.2011.03.010.

Mete, H. O., \& Zabinsky, Z. B. (2010). Stochastic optimization of medical supply location and distribution in disaster management. International Journal of Production Economics, 126(1), 76-84. http://dx.doi.org/10.1016/j.jpe.2009.10.004.

Murali, P., Ordóñez, F., \& Dessouky, M. M. (2012). Facility location under demand uncertainty: response to a large-scale bio-terror attack. Socio-Economic Planning Sciences, 46(1), 78-87. http://dx.doi.org/10.1016/j.seps.2011.09.001.

Noyan, N., Balcik, B., \& Atakan, S. (2015). A stochastic optimization model for designing last mile relief networks. Transportation Science, 50(3), 1092-1113. http://dx.doi.org/10.1287/trsc.2015.0621.

Orgut, l. S., lvy, J., Uzsoy, R., \& Wilson, J. R. (2016). Modeling for the equitable and effective distribution of donated food under capacity constraints. llE Transactions, 48(3), 252-266.

Paul, J. A., \& Wang, X. J. (2015). Robust optimization for United States Department of Agriculture food aid bid allocations. Transportation Research Part E, Logistics and Transportation Review, 82, 129-146. http://dx.doi.org/10.1016/j.tre.2015.08.001.

Pedraza-Martinez, A. J., \& Van Wassenhove, L. N. (2013). Vehicle replacement in the International Committee of the Red Cross. Production and Operations Management, 22(2), 365-376. http://dx.doi.org/10.1111/j.1937-5956.2011.01316.x.

Pérez-Rodríguez, N., \& Holguín-Veras, J. (2016). Inventory-allocation distribution models for postdisaster humanitarian logistics with explicit consideration of deprivation costs. Transportation Science, 50(4), 1261-1285. http://dx.doi.org/10.1287/trsc.2014.0565.

Peters, K., Silva, S., Gonçalves, R., Kavelj, M., Fleuren, H., Hertog, D., Ergun, O., \& Freeman, M. (2021). The nutritious supply chain: optimizing humanitarian food assistance. INFORMS Journal on Optimization, 3(2), 200-226. http://dx.doi.org/10.1287/ijoo.2019.0047.

Rancourt, M. E., Cordeau, J. F., Laporte, G., \& Watkins, B. (2015). Tactical network planning for food aid distribution in Kenya. Computers \& Operations Research, 56, 68-83. http://dx.doi.org/10.1016/j.cor.2014.10.018.

Rath, S., Gendreau, M., \& Gutjahr, W. J. (2016). Bi-objective stochastic programming models for determining depot locations in disaster relief operations. International Transactions in Operational Research, 23(6), 997-1023. http://dx.doi.org/10.1111/itor.12163.

Rawls, C. G., \& Turnquist, M. A. (2012). Pre-positioning and dynamic delivery planning for short-term response following a natural disaster. Socio-Economic Planning Sciences, 46(1), 46-54. http://dx.doi.org/10.1016/j.seps.2011.10.002.

Ribas, G. P., Leiras, A., \& Hamacher, S. (2012). Operational planning of oil refineries under uncertainty. IMA Journal of Management Mathematics, 23(4), 397-412. http://dx.doi.org/10.1093/imaman/dps005.

Rottkemper, B., Fischer, K., Blecken, A., \& Danne, C. (2011). Inventory relocation for overlapping disaster settings in humanitarian operations. OR Spectrum, 3(3), 721-749.

Salmerón, J., \& Apte, A. (2010). Stochastic optimization for natural disaster asset prepositioning. Production and Operations Management, 19(5), 561-574. http://dx.doi.org/10.1111/j.1937-5956.2009.01119.x.

Turner, R. (2013). Modelling barriers to customs entry at the time of disaster in developing countries - mitigating the delay of life-saving materials (Maters thesis). University of Lugano, Switzerland.

United Nations. (2018). The Sustainable Development Goals Report 2018. New York: United Nations. Retrieved in 2021, June 2, from https://unstats.un.org/sdgs/files/report/2018/TheSustainableDevelopmentGoalsReport2018-EN.pdf.

Whybark, D. C. (2007). lssues in managing disaster relief inventories. International Journal of Production Economics, 108(1-2), $228-235$. http://dx.doi.org/10.1016/j.jpe.2006.12.012.

World Customs Organization. (2015). Retrieved in 2017, September 14, from http://www.wcoomd.org/en/about-us/wco-members/ membership.aspx.

World Food Programme (2016). WFP Ethiopia Country Brief December 2016. Retrieved in 2017, September 14, from http://documents. wfp.org/stellent/groups/public/documents/ep/wfp273887.pdf

World Food Programme. (2011). Facts Blast - Foods Purchase in 2010. May, 2011. Retrieved in 2017, September 14, from http:// documents.wfp.org/stellent/groups/public/documents/communications/wfp187701.pdf

World Food Programme. (2015). Retrieved in 2017, September 14, from http://www.wfp.org.

Yigezu, A. Y., \& Sanders, J. H. (2012). Introducing new agricultural technologies and marketing strategies: a means for increasing income and nutrition of farm households in Ethiopia. African Journal of Food, Agriculture, Nutrition and Development, 12(5), 6365-6384. 